\title{
Rock slope stabilization: A case study of a weathered sandstone slope along the railway in Bavaria, Germany
}

\author{
Lopamudra Dutta and Gourango Singha \\ Geobrugg India Pvt Ltd \\ Gurgaon, India \\ lopamudra.dutta@geobrugg.com
}

\begin{abstract}
Due to the fact that the German Railroad reduced the maintenance work on the important railway line Nuremberg - Regensburg, section Deining - Batzhausen they had several cases with blocks laying at the tracks. Therefore they decided to stabilize the $70^{\circ}$ steep weathering prone sandstone slope. As a protective measure the flexible slope stabilization system using high-tensile steel wire meshes was selected in combination with nailing. This widely used way to stabilize soil and rock slopes is economical and a good alternative to shotecrete solutions or massive supporting structures. Special concepts have been developed for dimensioning of flexible surface stabilization systems in steeper soil or heavily weathered loosened rock slopes, but also on jointed and layered rock in which the bodies liable to break out are determined by joint and layer planes. Stabilizations implemented in soil and rock slopes confirm that these measures are suitable for practical applications. Analyzing of the design, explanation of the installation and how the finished installation behaves will be shown.
\end{abstract}

Keywords-RUVOLUM, TECCO, dimensioning, flexible slope stabilization system

\section{INTRODUCTION}

The use of flexible slope stabilization systems have proven there suitability around the world, including Europe, Asia, North America and in colder climates, where the stabilizing facings need to be able to flex under the freeze/thaw cycle. Historically, the mesh used for these purposes is produced using mild steel wire with a tensile strength of $400-500 \mathrm{~N} / \mathrm{mm}^{2}$. The development of mesh made from high-tensile steel wire with a tensile strength of at least $1770 \mathrm{~N} / \mathrm{mm}^{2}$, offers new possibilities for the efficient and economical stabilization of slopes (see Fig. 1). Sophisticated dimensioning concepts serve to dimension these kinds of slope stabilization systems against superficial instabilities by taking the statics of soil and rock into account.

\section{PROJECT}

On the important German railway line Nuremberg -
- Regensburg, section Deining - Batzhausen they had several

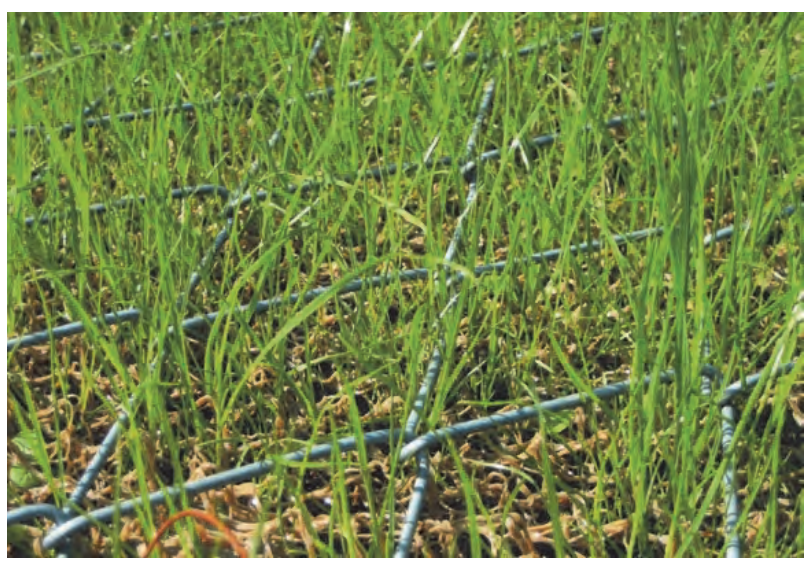

1(a)

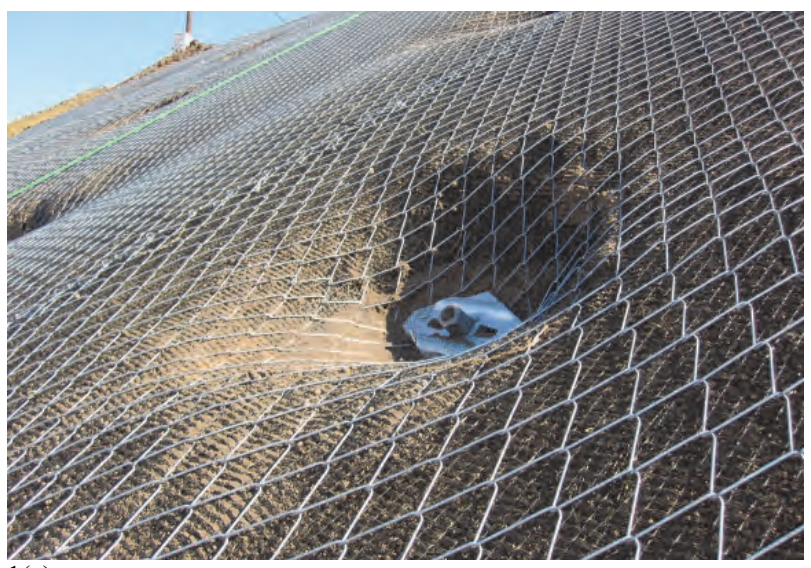

1(a)

Fig. 1. High-tensile wire mesh for slope stabilization (left) and system spike plate to tension the high-tensile steel wire mesh against the slope surface (right).

cases with blocks laying at the tracks afterwards they reduced the maintenance work on this section. Therefore they decided to active stabilize the $70^{\circ}$ steep, up to $15 \mathrm{~m}$ high work on this section. Therefore they decided to active stabilize the $70^{\circ}$ steep, up to $15 \mathrm{~m}$ high and weathering 
prone sandstone slope. A protective measure had to be selected to stabilize the $8500 \mathrm{~m}^{2}$ of the exposed cutting

against superficial instabilities, tilting as well as sliding of individual blocks and rockfall.

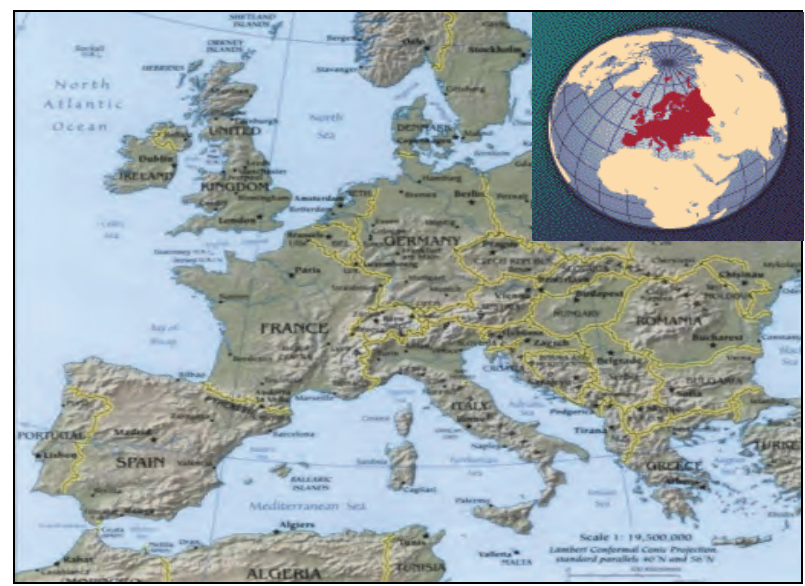

2(a)

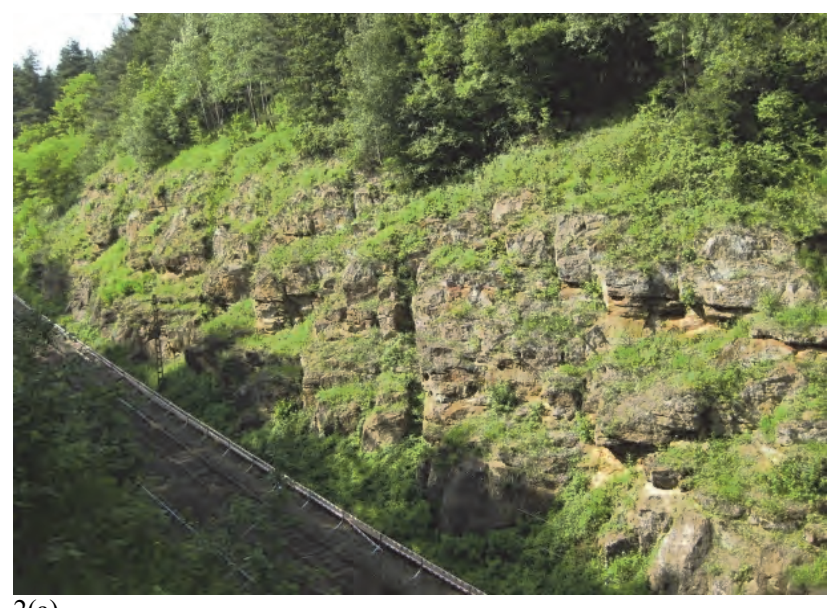

2(a)

Fig. 2. Location of the project in the area of Deining illustrated (left) and partly eroded rock slope before the installation work (right).

TABLE I PARTIES INVOLVED

\begin{tabular}{ll}
\hline Client: & $\begin{array}{l}\text { German Railway AG, } \\
\text { Nuremberg, Germany }\end{array}$ \\
Project: & $\begin{array}{l}\text { CDM Consult GmbH, Munich, } \\
\text { Germany }\end{array}$ \\
$\begin{array}{l}\text { Nailing and system } \\
\text { installation: }\end{array}$ & $\begin{array}{l}\text { SPESA GmbH, Schrobenhausen, } \\
\text { Germany }\end{array}$ \\
Date of installation: & $\begin{array}{l}\text { July 2009 - May 2010 } \\
\text { (including winter break) }\end{array}$ \\
\hline
\end{tabular}

The flexible slope stabilization system consists of TECCO G65/3 high-tensile steel wire mesh, system spike plates and soil nails has been selected. The mesh is made from $3 \mathrm{~mm}$ high tensile wire and uses a zinc-aluminum coating for protection against corrosion. Each diamond of the single twist mesh measures $83 \mathrm{~mm} \times 143 \mathrm{~mm}$. The high tensile steel wire used in the manufacture of the mesh has a tensile strength of $1770 \mathrm{~N} / \mathrm{mm}^{2}$, compared to mild steel

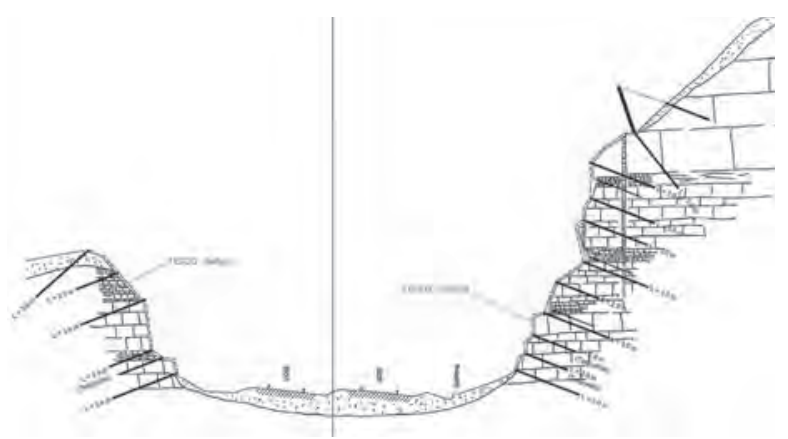

Fig. 3. Typical cross-section including protection measure.

which has a tensile strength of $400-500 \mathrm{~N} / \mathrm{mm}^{2}$. As a result TECCO G65/3 mesh has a tensile strength of $150 \mathrm{kN} / \mathrm{m}$

\section{PROTECTION MEASURE}

, which means substantially higher forces can be absorbed by this mesh in comparison to conventional mild steel wire mesh. Aside from the higher bearing capacity, another advantage of TECCO mesh over conventional mild steel wire mesh is that it has an even load transmission and no weak zones within the mesh. This is achieved by manufacturing TECCO mesh with the same diameter high tensile wire, which forms a unified and homogenous mesh structure.

Special diamond-shaped system spike plates which match the load capacity of the mesh serve to fix the mesh to soil or rock nails. By tensioning these nails, and recessing the spike plates into the ground, the mesh is adequately tensioned to ensure it follows the surface contours.

With this slope stabilization system the rows of nails are offset to each other by half a horizontal nail distance. This limits the maximum possible break out between the individual nails to a width "a" and a length of " 2 x b" (see Fig. 4, left). The staggered layout is shown in Fig. 4 (right) for the project Dongcheon in Korea.

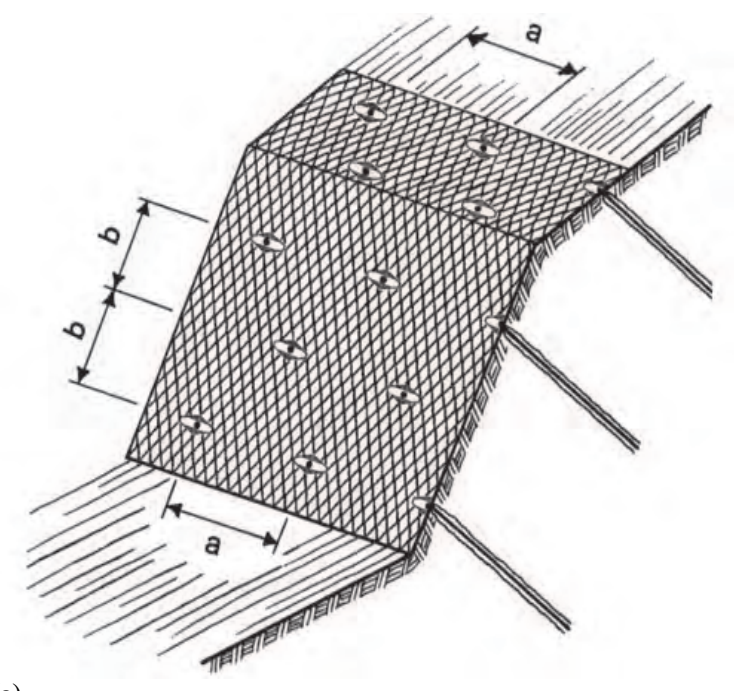




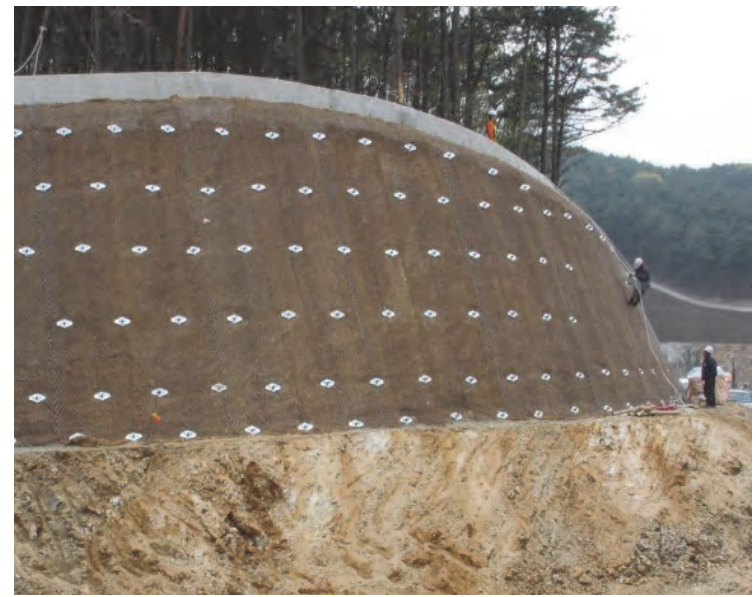

4(b)

Fig. 4. General profile with nail arrangement (4a) and staggered pattern of nail installation - Project Dongcheon, Korea (4b).

\section{DIMENSIONING}

The flexible slope stabilization system was dimensioned against superficial instabilities based on the RUVOLUM concept (Rüegger and Flum 2006). The maximum nail spacing and the required nail length can be determined, and by utilizing the high bearing capacity of the mesh, significant cost savings can be realized by reducing the number of nails required. Conventional slope design methods are still required for deeper seated failure mechanisms.

\section{INSTALLATION}

Firstly, the slope was cleaned of eroded soil and smaller loose rocks. Due to the fact that there was no access to the top of the slope, the installation company decided to install the nails from scaffolding (see Fig. 6). It was very important that the nails could been installed in deep seated spots so that the mesh could been tensioned and kept in contact with the surface. Shotcrete was used at locations where undercutting was occurring, to further secure any blocks from sliding down.

\begin{tabular}{|l|l|}
\hline Height of the slope: & $10-15 \mathrm{~m}$ \\
\hline Subsoil: & $\begin{array}{l}\text { Variable weathered } \\
\text { sandstone (partly eroded) }\end{array}$ \\
\hline Inclination of the slope: & $70^{\circ}$ \\
\hline Stabilized area: & $8^{\prime} 500 \mathrm{~m}^{2}$ \\
\hline Nail type: & Gewi $ø 32 \mathrm{~mm}$ \\
\hline Nail pattern: & $2.0 \times 2.0-2.6 \times 2.6 \mathrm{~m}$ \\
\hline Nail length: & $\mathrm{L}=2-5 \mathrm{~m}$ \\
\hline Mesh type: & $\begin{array}{l}\text { High-tensile steel wire } \\
\text { mesh TECCO G65 / } 3 \mathrm{~mm}\end{array}$ \\
\hline Spike plates: & System spike plate \\
\hline
\end{tabular}

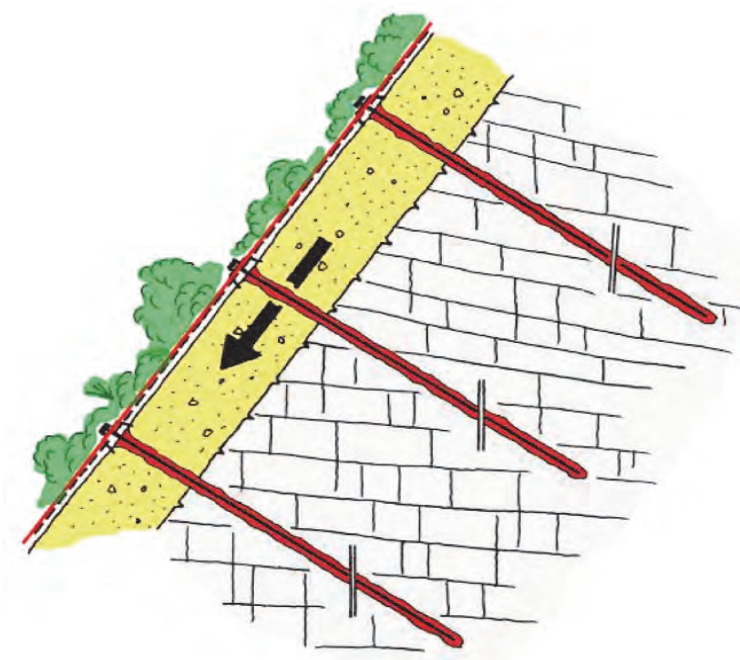

$5(a)$

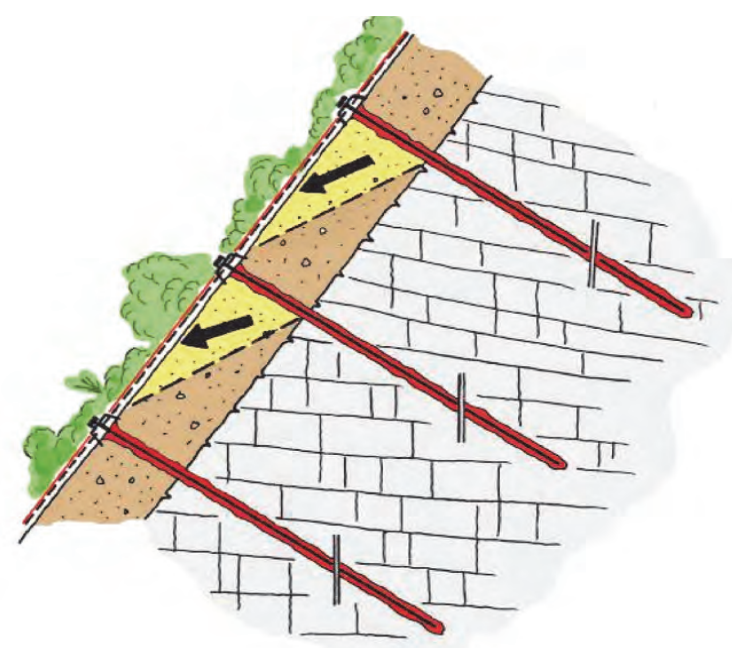

5 (b)

Fig. 5. The dimensioning concept is based on the investigation of superficial slope-parallel instabilities (5a) and on the investigation of the local instabilities between single nails $(5 \mathrm{~b})$.

\section{RE-VEGETATION / EROSION PROTECTION}

Erosion control mats can be installed underneath the mesh to aid in re-vegetation. The application of a vegetation layer can be limited by the soil or rock properties, groundwater and climate. The steeper the slope cutting, the more difficult it becomes for vegetation to grow. If re-vegetation is to be carried out, a species of plant or grass should be selected that is fast growing and suitable for the local conditions.

\section{CONCLUSIONS}

The TECCO slope stabilization system can be adapted to the site specifics and static conditions in a very flexible manner. The system can be designed and dimensioned against superficial instabilities, which is the first time flexible surface support measures can be properly designed. This approach offers the possibility to arrange the nails in a 

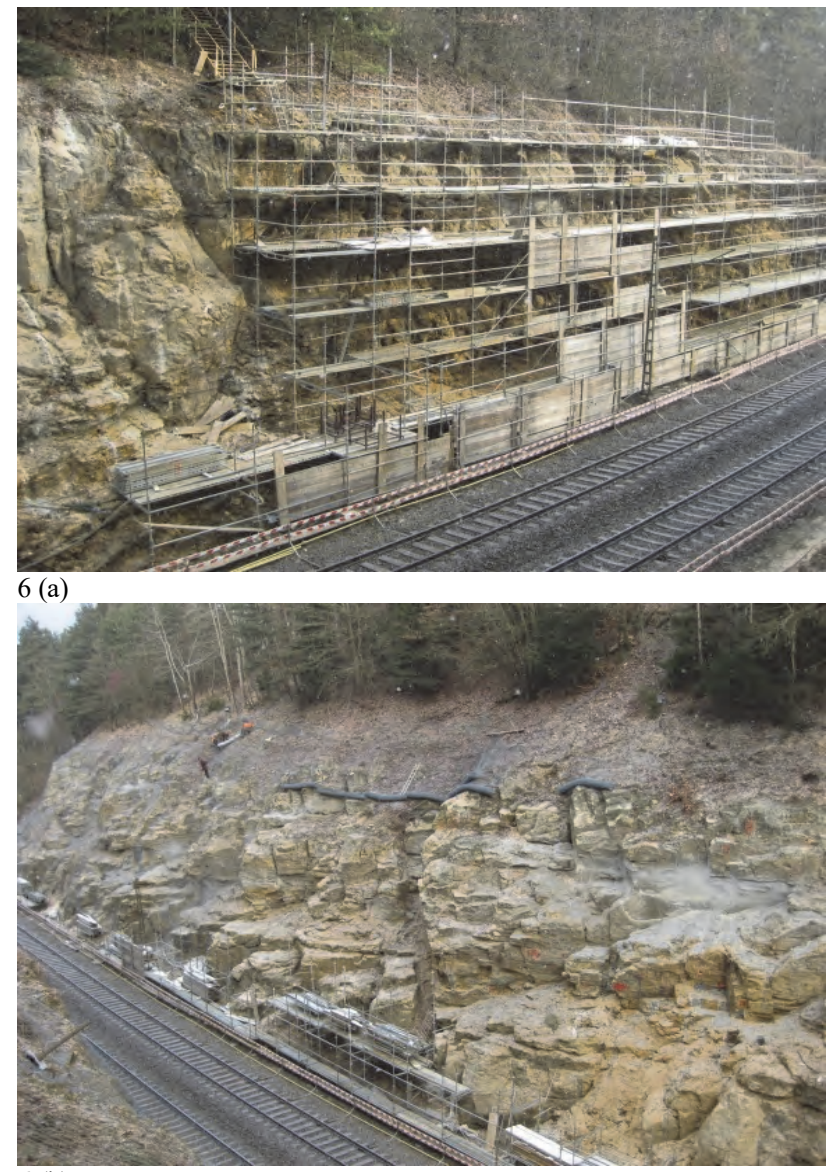

6 (b)

Fig. 6. (a \& b) Scaffold for drilling after cleaning of the slope (left) and beginning installation of the mesh (right).

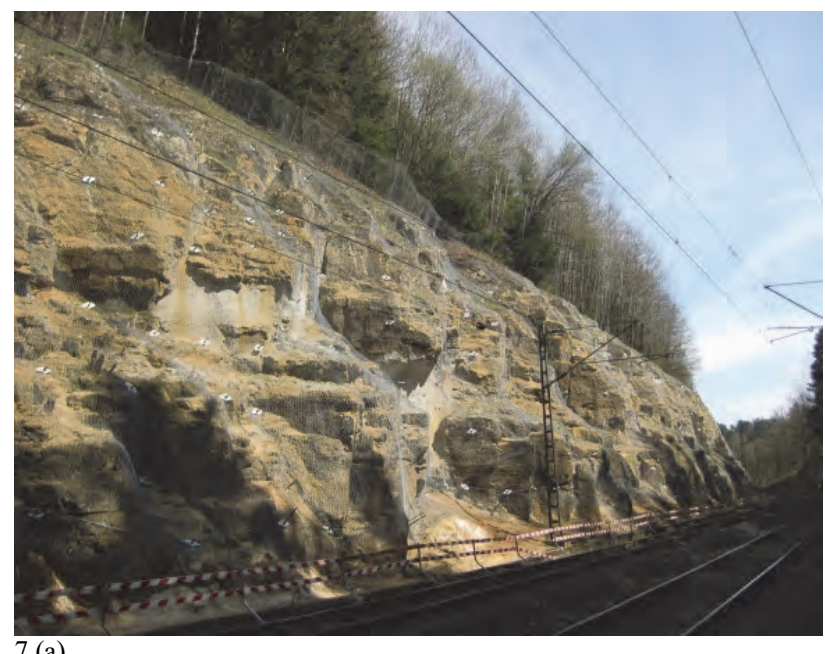

7 (a)

more economical way due to the capability of TECCO mesh in absorbing and transferring high loads. When slopes stabilized with flexible high tensile steel wire mesh are combined with erosion control mats, they can regain a natural or vegetated appearance, which aesthetically is normally preferred.

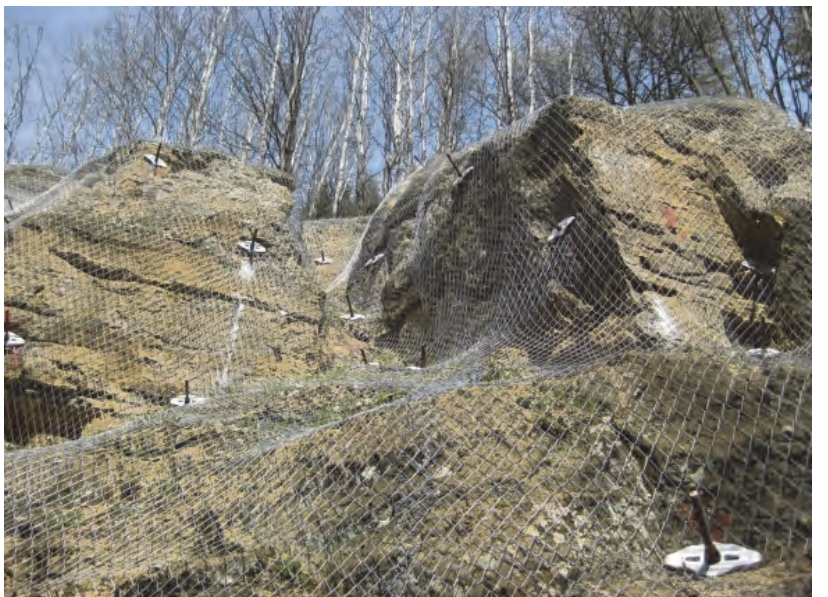
7 (b)

Fig. 7. (a \&b) Overview and nail pattern adapted to the local situation (left) and adaptability of the installed mesh (right).
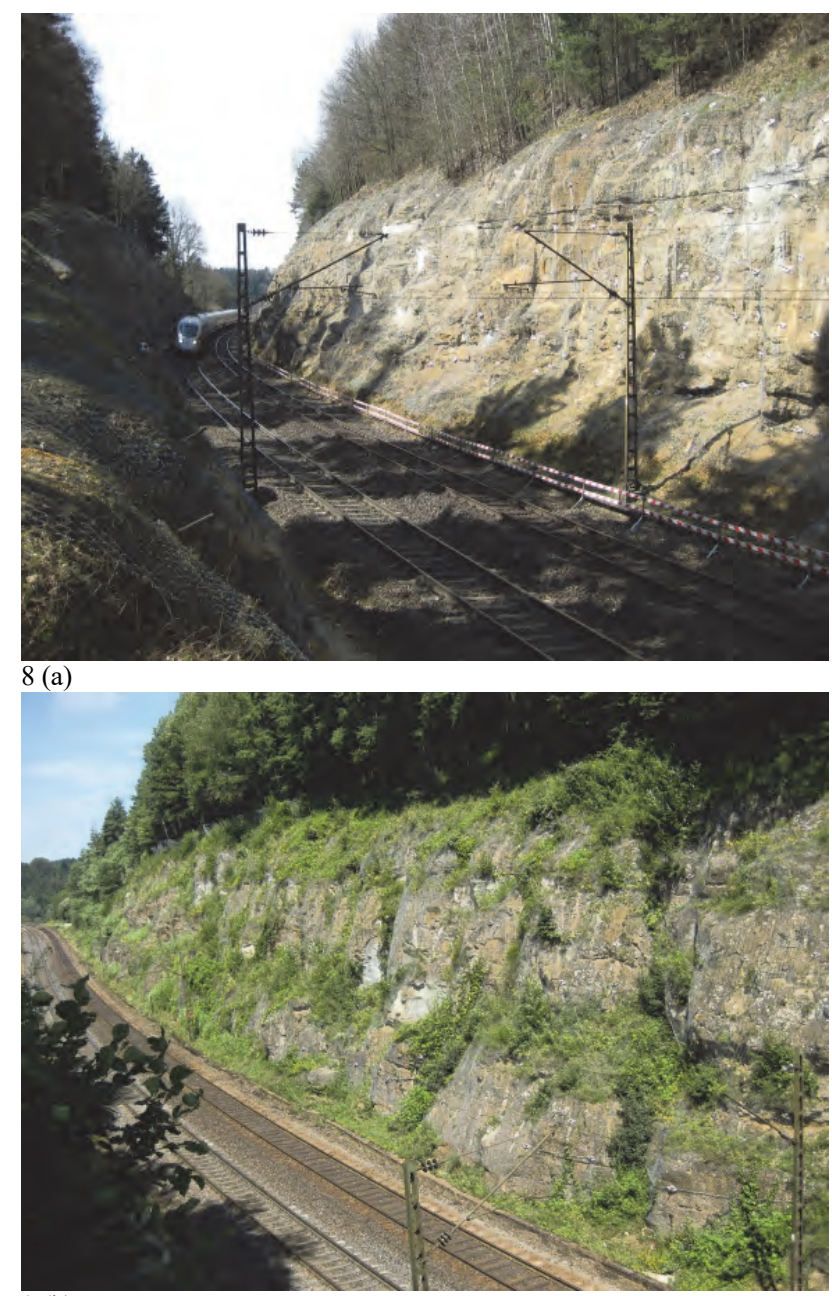

8 (b)

Fig. 8. Condition of the slope in April 2010 (left) and in July 2011 (right) successful re-vegetation. 


\section{REFERENCES}

[1] Brändlein P. (2004). LGA Nuremberg, Germany, Monitoring and supervision of laboratory testing of the TECCO slope stabilization system, Test report BPI 0400046/1.

[2] Rüegger, R.; Flum, D. (2006). Anforderungen an flexible Böschungsstabilisierungssysteme bei der Anwendung in Boden und Fels. Technische Akademie Esslingen, Beitrag für 4. Kolloquium, Bauen in Boden und Fels".

[3] Rüegger, R.; Flum, D.; Haller, B. (2002). Hochfeste Geflechte aus Stahldraht für die Oberflächensicherung in Kombination mit Vernagelungen und Verankerungen. Technische Akademie Esslingen, Beitrag für 2. Kolloquium „Bauen in Boden und Fels“. 